Escritura y Pensamiento

20-24(40-48), 2021, 267-288

\title{
LA ESTÉTICA DADAÍSTA EN LA CONSTRUCCIÓN DEL VERSO LIBRE EN “CHINFONÍA BURGUESA" DE JOSÉ CORONEL URTECHO Y JOAQUÍN PASOS
}

\section{THE DADA AESTHETIC IN THE CONSTRUCTION OF THE FREE VERSE IN "CHINFONÍA BURGUESA" BY JOSÉ CO- RONEL URTECHO AND JOAQUÍN PASOS}

\section{A ESTÉTICA DADAÍSTA NA CONSTRUÇÃO DO VERSO LIVRE EM "CHINFONÍA BURGUESA" DE JOSÉ CORONEL URTECHO E JOAQUÍN PASOS}

César Antonio Hurtado López ${ }^{1}$ Universidad Nacional Mayor de San Marcos cesar.hurtado3@unmsm.edu.pe ORCID: 0000-0002-2600-0880

Recibido: 20/02/21

Aceptado: 8/03/21

1 César Antonio Hurtado López (Lima, 1997). Estudiante de pregrado en la carrera de Literatura en la UNMSM. Ha publicado textos de creación en dos antologías a cargo de la editorial Gallito de las Rocas. Actualmente dirige la revista Fotogramas de papel e investiga sobre los alcances de versolibrismo en el poemario Zona Dark (1991) de Monserrat Álvarez. 


\title{
Resumen
}

Este artículo estudia los elementos de la estética dadaísta que configuran el verso libre en el poema "Chinfonía burguesa" desde el enfoque teórico de la versología moderna. Se plantea como hipótesis que en el verso libre de los autores se actualizan estrategias discursivas de impronta dadaísta como el uso semántico del espacio, rimas y los paralelismos para plantear una crítica a las concepciones burguesas desde el marco de la irracionalidad. Así, el trabajo explora los alcances de la estética dadaísta, su relación con el verso libre en Hispanoamérica y su aplicación en el poema a través de un análisis formal e interpretativo.

Palabras clave: Dadaísmo, verso libre, poesía nicaragüense, Joaquín Pasos, José Coronel Urtecho.

\begin{abstract}
This article studies the elements of Dada aesthetic that shape the free verse in the poem "Chinfonia burguesa" from the theoretical approach of modern versology. It is propounded as a hypothesis that the discursive strategies of Dada imprint, such as the semantic use of space, rhymes, and parallelisms, are updated in the free verse of the authors to propose a critique of bourgeois conceptions from the framework of irrationality. By doing so, the paper explores the scope of Dada aesthetic, its relation with the free verse in Hispanic America and its application within the poem all through a formal and interpretative analysis.
\end{abstract}

Keywords: Dada, free verse, Nicaraguan poetry, Joaquín Pasos, José Coronel Urtecho.

\section{Resumo}

Este artigo estuda os elementos da estética Dadaísta que configuram o verso livre no poema "Chinfonía burguesa" a partir do enfoque teórico da versologia moderna. A hipótese proposta neste artigo é que no verso livre dos autores são atualizadas estratégias discursivas do dadaísmo como o uso semântico do espaço, rimas e os paralelismos para propor uma crítica às concepções burguesas a partir da irracionalidade. Então, o projeto explora o alcance da estética dadaísta, sua relação com o verso livre na América Latina e sua aplicação no poema por meio de uma análise formal e interpretativa.

Palavras-chave: Dadaísmo, verso livre, poesia nicaraguense, Joaquín Pasos, José Coronel Urtecho. 


\section{Introducción}

El modernismo hispanoamericano, desde su condición heterogénea, permitió los primeros ejercicios de creación con el verso libre a través de una experimentación con los elementos fónicos fundamentales. En ese sentido, autores como Ricardo Jaimes Freyre en Castalia bárbara (1899) o Manuel González Prada en Exóticas (1911) constituyen aproximaciones al fenómeno versolibrista desde el horizonte modernista. En ambos casos, destaca el haber advertido un cambio en el paradigma estético de la región.

Sobre dicho cambio profundizaron autores como Vicente Huidobro o Jorge Luis Borges, en el marco de la asimilación de los proyectos estéticos de la vanguardia europea. De esta manera, la década del 20 fue el periodo de mayor impacto de los diferentes ismos en Latinoamérica, los cuales fueron empleados como registros expresivos sobre los cuales se construyeron proyectos nacionales y personales.

Un texto fundamental sobre aquel momento de influjo vanguardista es el Índice de la nueva poesía americana (1926), prologado por autores de renombre como los mencionados en el párrafo anterior y el peruano Alberto Hidalgo. Dentro de dicha antología, el único autor nicaragüense incluido es Salomón De la Selva, en cuyo trabajo poético se puede advertir un manejo del verso libre que dialoga con formas clásicas como el heptasílabo y el endecasílabo.

Si bien De la Selva era considerado un autor de vanguardia importante, la figura de Rubén Darío todavía constituía un paradigma inamovible durante la década del 20 en Nicaragua. Así, el inicio de la década del 30 se encuentra marcado por el movimiento vanguardia, cuya revista congrega a importantes autores como Pablo Antonio Cuadra, José Coronel Urtecho y Joaquín Pasos. Estos dos últimos publican en 1931 el poema "Chinfonía burguesa", el cual cuenta con una presentación en la que se reflexiona sobre los aspectos formales del texto. 
De esta manera, el poema de Urtecho y Pasos, así como el texto introductorio a cargo de este último, se insertan dentro del corpus de los manifiestos de vanguardia, los cuales coincidieron en la relevancia del verso libre como un sistema prosódico que permitía representar una sensibilidad nueva y cuestionar el canon poético imperante en la región. Sin embargo, el quehacer versolibrista de los autores mencionados solo puede dimensionarse correctamente en función de la tradición que buscaban subvertir, de manera que el verso libre es un sistema prosódico con la facultar de dialogar con la versificación regular y otros horizontes estéticos que contemplan (por ejemplo) la dimensión visual del poema.

En este sentido, es pertinente identificar las características del verso libre presentes en "Chinfonía burguesa" y su relación con la estética dadaísta bajo la óptica de la versología moderna. Así, se emplearán los postulados teóricos de Pedro Henriquez Ureña (2003) y Oldrich Belic (2000), sumados a un análisis apoyado en las consideraciones de Raúl Gustavo Aguirre (1968) sobre el poema dadaísta.

\section{Los alcances de la estética dadaísta}

En primer lugar, es necesario identificar los elementos que configuran la denominada estética dadaísta, la cual se encuentra vinculada profundamente a la tradición occidental pese a que propugne la negación total de las convenciones artísticas de orden racional. Para dicho propósito se situará al dadaísmo dentro del marco de las vanguardias históricas, de manera que pueda comprenderse su alcance a nivel ideológico y estético.

La irrupción de las vanguardias históricas en Europa y su inmediata influencia en Hispanoamérica no constituyó un fenómeno aislado, sino que respondió a un malestar generalizado a nivel político y social a principios del siglo XX. Asimismo, en el ámbito estético, desde el Romanticismo (y la reforma de los principios aristotélicos) ya se había reconfigurado la forma de 
entender la creación literaria, preponderando la libertad subjetiva del artista.

Dicha libertad, a medida que se desarrollaron otros horizontes estéticos como el simbolismo en Europa y el modernismo en América, fue adquiriendo nuevos matices, de manera que la llegada del vanguardismo literario fue un estallido estilístico e ideológico gestado desde la misma tradición. De esta manera, no es extrañar que prácticas como la escritura automática se hayan institucionalizado años más tarde.

Por un lado, Carlos Fajardo (2011) advierte una característica de las vanguardias que resulta fundamental para el desarrollo del siguiente apartado. Tanto el dadaísmo como el surrealismo, al mostrarse críticos con la razón burguesa, proponen proyectos que enuncian desde los márgenes de la racionalidad. En ese sentido, los autores de vanguardia se mostraron entusiastas ante los "múltiples y diversos discursos no occidentales que fueron estudiados y asimilados en sus experimentaciones". (Fajardo, 2011, p.13). Dentro de dichos discursos se encontraban las tradiciones populares de regiones consideradas no tan occidentalizadas como Centro América o África.

Es importante resaltar también la figura del infante, cuya enunciación ha sido vinculada a la escritura automática surrealista y el absurdo relacionado a la pureza artística en caso del dadaísmo. Sobre este último punto, es necesario señalar que incluso la concepción del término dadá se relacionaba al contexto de un infante, puesto que se tenía como "una palabra infantil que designa a un caballo de madera" (L'Ecotais, 1998, p. 8).

Por otro lado, Guillermo De Torre (1965) postula que el vanguardismo europeo tuvo dos ejes principales: el internacionalismo y el anti-tradicionalismo. El primero, que para el autor tiene sentido en la "extensión ecuménica del espíritu" (De Torre, 1965, p. 24), hace referencia a un sentimiento de unidad global en demérito de la tradición, rechazando que las nuevas vias ex- 
presivas se suscriban a la tradición artística de una nación en específico. Por su parte, del segundo eje se desprenden aspectos como el trastrocamiento de los elementos de la tradición y la exaltación de la originalidad.

Sin embargo, Terry Eagleton (2017), quien profundiza en el concepto de la originalidad, postula que esta no puede entenderse como una categoria totalizadora. Como ya se ha explicado, todas las obras, por más revolucionarias que se presenten, tienen la necesidad de dialogar con la tradición precedente para poder ser comprendidas. Así, incluso el ismo más radical de la vanguardia, el dadaísmo, si bien buscó romper con todos los preceptos artísticos decimonónicos, mantuvo cierto sentido de belleza a través de la subversión.

De esta manera, las obras del dadaísmo, pese a alejarse del sentido común, intentaban enunciar en función de condiciones preexistentes, creando una ruptura en la tradición a partir del diálogo con ella. Dicho diálogo era operado mediante diversos mecanismos concretos como la ironía, la yuxtaposición de elementos no relacionados y el cuestionamiento. Al respecto, Raúl Gustavo Aguirre (1968), quien reconoce la influencia en Dadá de otros ismos como el futurismo, el cubismo y el expresionismo, establece algunas consideraciones sobre el poema dadaísta.

En primer lugar, propone que el uso del azar como ejercicio creativo constituye un efecto en lugar de una estrategia discursiva, de manera que "el poema dadaísta mantiene, aun en su época más pura, un sustrato de coherencia que lo señala como algo diferente de un producto del mero azar" (Aguirre, 1968, p. 40). Así, el autor ahonda en los mecanismos que posibilitan dicho efecto de incoherencia, encontrando en la preocupación por cada aspecto del lenguaje - y en especial por la dimensión eufónica - una herramienta para generar significaciones.

En ese sentido, el poema dadaísta tiende a destacar la cualidad fonética del lenguaje a través de "juegos de palabras, onomatopeyas, dialectos y lenguajes técnicos, (establecien- 
do) relación entre las palabras por su sonido antes que por su significación lógica" (Aguirre, 1968, p. 41). Dicha forma de estructurar el discurso dadaísta se conecta directamente con la búsqueda de una pureza en el arte, puesto que se construye un lenguaje que rompe con los esquemas convencionales para instaurarse como un hecho estrictamente artístico.

Asimismo, cabe mencionar que elementos fónicos fundamentales como el ritmo y la rima, de claro cuño tradicional, se mantienen de forma constante en el quehacer dadaísta, construyendo - por ejemplo- textos que se alejan conscientemente de la noción buen gusto o que representan el absurdo desde una mirada que transita entre lo racional e irracional. A continuación, un ejemplo de este último punto, extraído del poemario De nos oiseaux (1923):

la canción de un dadaísta que no era ni alegre ni triste y que amaba una bicicleta que no era ni alegre ni triste (Tzara, 1923, s.n.)

A partir del fragmento citado, es pertinente relacionar el quehacer dadaísta con la variable del verso libre. Como ya ha quedado claro, la repetición de sonidos es fundamental para configurar el poema dadaísta, de manera que el verso libre constituye un sistema prosódico fundamental para la representación del absurdo puesto que permite desistir del isosilabismo y focalizar la atención en, por ejemplo, el juego con los paralelismos, entendiéndolos como el uso consciente de recurrencias léxicas, anafóricas y semánticas para construir el ritmo.

Los mecanismos mencionados también se encuentran presentes en la estética surrealista, constituyendo las bases de la escritura que practicarian autores como Breton, Aragon o Eluard. Ambos movimientos, si bien compartieron convicciones como el rechazo a la razón y el sentido crítico hacia los valores burgueses, se diferenciaron principalmente en el entendimiento del devenir artístico. Mientras el dadaísmo propugnaba una 
negación total, entendida como una respuesta nihilista ante el sentido absurdo de la existencia, los surrealistas planteaban la necesidad de un cambio en el quehacer artístico y politico.

Adicionalmente, existen notables diferencias entre los manifiestos redactados por Tristán Tzara y André Bretón pese a que comparten un contexto de enunciación similar. En primer lugar, Tzara en Siete manifiestos dada (1924) configura una tensión entre una lógica coherente y otra incoherente a través de una prosa altamente crítica, que utiliza la ironía y la yuxtaposición de elementos no relacionados para reforzar su discurso y la sensación de absurdo.

Por su parte, el primer manifiesto del surrealismo, escrito por Breton seis años después del primer manifiesto dadaísta, presenta un tono más ensayístico, donde la ironía cumple un papel complementario y es la exposición de ideas el aspecto central. Así, el manifiesto discurre sobre la potencia del sueño y la necesidad de adentrarse en el inconsciente. Estos últimos dos conceptos hacen del surrealismo una propuesta diferente a nivel conceptual, lo cual también repercute en la dimensión estética.

Por eso es necesario establecer una diferenciación entre ambos movimientos, puesto que la historia literaria muchas veces ha clasificado al dadaísmo como solo un antecedente del surrealismo, lo cual, si bien es cierto, resulta inexacto. En cuanto al planteamiento conceptual del movimiento, el surrealismo es en gran medida una superación de los aportes dadaístas. No obstante, en materia estética se observan determinadas predilecciones que hacen evidente la presencia de dos tendencias diferentes.

Ambos movimientos emplean la yuxtaposición de elementos no relacionados, lo cual deviene en un tipo particular de metáforas que apelaron a una nueva sensibilidad en su contexto de enunciación. Sin embargo, el surrealismo centra su atención en la noción de automatismo, apelando a la manifestación del 
inconsciente a través de las imágenes planteadas en el poema, mientras que el dadaísmo plantea una preocupación por el lenguaje irracional como mecanismo para generar significaciones a través de estrategias como los juegos de palabras o las onomatopeyas.

Finalmente, pese a mantener una posición contraria a lo señalado hasta el momento, es pertinente mencionar lo señalado por Emmanuelle de L'Ecotais en El espiritu Dada (1998):

Pero, si bien su vida fue bastante corta (muere oficialmente en 1924, con el nacimiento del Surrealismo), su posteridad fue grande. No fue, sin embargo, su "estilo" quien hizo escuela, ya que no hay "un estilo dadá" — de hecho, no decimos Dadaísmo, sino Dadá - , pero sí su espíritu basado en la ironía, la duda, la provocación, la anarquía, la revolución y la negación en bloque de todos los valores de la sociedad moderna. (L'Écotais, 1998, p. 20)

Cabe mencionar que la investigadora se refiere al dadaísmo como manifestación artística en general, por lo su ensayo no repara en las particularidades explicadas sobre el poema dadaísta. Sin embargo, la alusión a un espíritu indica la flexibilidad de dicha estética para ser adaptada a nuevos contextos de enunciación. Tal es el caso del poema "Chinfonía Burguesa", perteneciente a la vanguardia nicaragüense.

\section{Presentación de la "Chinfonia burguesa" y la re- flexión sobre el verso libre}

Es pertinente dimensionar el contexto poético en que se enmarcó el trabajo de Urtecho y Pasos, por lo que se explicarán algunos aspectos fundamentales. En primer lugar, Ernesto Cardenal (1982) considera que José Coronel Urtecho fue el introductor de la poesía de vanguardia en Nicaragua, puesto que su regreso al país en 1927 tras una estancia en Estados Unidos permitió el acceso a nuevas literaturas. En ese sentido, el autor identifica en el poema "Oda a Rubén Darío" un primer manifiesto sobre el 
cambio de paradigma estético al señalar que "la poesía ya había cambiado de traje" (Cardenal, 1982, p. 71). Asimismo, resulta fundamental la presencia de la burla para desacralizar una figura como la de Darío, alejándose de la retórica modernista y los elementos considerados exclusivamente cosmopolitas.

Es así como, alrededor de la figura de Urtecho, surge en la ciudad de Granada el movimiento vanguardia, cuyos integrantes encontraron en el escándalo una forma de generar expectativa sobre el fenómeno literario. El reconocido poeta y crítico apunta también que el movimiento, así como la revista que produjo, tuvo un claro espíritu nacionalista, proponiendo una renovación en la poesía nicaragüense tan marcada por los seguidores del estilo de Dario: "Nacionalismo y poesía los habían llevado al pueblo, y este contacto con el pueblo les daba vitalidad y humor" (Cardenal, 1982, p. 74).

Dicho contacto con el pueblo, que también se encuentra en la presentación de "Chinfonía burguesa", se relaciona directamente con la presencia de un tono juvenil. Al respecto, Cardenal repara en la edad (dieciocho años) en que comienza el quehacer poético de autores pertenecientes al movimiento como Pablo Antonio Cuadra y Joaquín Pasos. Además, asimilando el anti-tradicionalismo propio de las vanguardias históricas, el grupo surgido a finales de la década del 20 se había propuesto construir una literatura propia, por lo que sus textos experimentales se entendían como una infancia literaria en la formación de la poesía nicaragüense.

Cardenal concluye que el principal aporte del grupo vanguardia fue el haber propuesto nuevos derroteros expresivos, alejándose de la retórica modernista para poetizar a partir de "las canciones, teatro, oraciones, villancicos y romances del pueblo" (Cardenal, 1982, p. 76). Al respecto, Pedro Xavier Solís (2001) coindice con Cardenal al identificar un amplio horizonte de influencias para los autores del movimiento, que van desde la poesía popular nicaragüense hasta las figuras latinoamericanas pertenecientes a la vanguardia de la década del 20. 
El investigador también señala que el movimiento vanguardia fue el único que se articuló como grupo en Centroamérica, de manera que sus autores comparten no solo códigos estéticos, sino también ideológicos y políticos (Solís, 2001). Dicha afirmación permite comprender de mejor manera el interés de Joaquín Pasos y José Coronel Urtecho al colaborar en la creación de "Chinfonía burguesa", dado que compartían unos mismos ideales respecto a su contexto nacional.

En ese sentido, no es de extrañar que en El movimiento de vanguardia en Nicaragua. Análisis y Antologia (2003) se incluya tanto a la "Chinfonía burguesa" como a la presentación a cargo de Joaquín Pasos en una sección denominada "Contra el espíritu burgués". Así, el texto analizado se inserta dentro de un corpus mayor y, en consecuencia, responde a ciertas características del movimiento de vanguardia y del formato de manifiesto.

Respecto a dicho formato textual, Alessandra Chiriboga Holzheu (2014) señala que "el manifiesto es, por excelencia, un género moderno porque expresa en forma y contenido una transición y un desplazamiento" (Chiriboga, 2014, p. 24). Dicho desplazamiento resulta significativo para las vanguardias históricas, puesto que les permiten discurrir sobre el presente estético e ideológico desde una posición subjetiva o colectiva, produciendo diversas transformaciones en el devenir artístico.

En el caso del contexto nicaragüense, Joaquín Pasos configura un discurso que se alinea con los postulados del grupo vanguardia al manifestar una preocupación por lo nacional y el cuestionamiento al burgués. Sobre este último punto, Giuseppe Bellini (2010) señala lo siguiente en el marco de la intervención estadounidense en Nicaragua:

La cuestión nacional acentúa el conflicto entre los vanguardistas y una burguesía pasiva frente a la presencia extranjera, o, lo que es peor todavía, favorable a ella. La ideología del grupo y su postura son claras: rechazo de lo extraño, búsqueda y valorización de lo autóctono, restauración de la 
identidad del país, que se opone a la presencia y a la cultura yankee. (Bellini, 2010, p. 13)

Después de lo expuesto, es pertinente señalar que la variable del verso libre se inserta dentro del denominado manifiesto vanguardista hispanoamericano como una pieza fundamental, puesto que permite una mayor amplitud expresiva y logra canalizar el sentir revolucionario de los autores influenciados por los horizontes estéticos mencionados. Sin embargo, es necesario remarcar que el verso libre presenta una condición dialogante, la cual implica una relación orgánica con la tradición, de manera que los elementos fónicos fundamentales se actualizan en las diferentes poéticas de principios del siglo XX.

Por ejemplo, Leopoldo Lugones (1909) aboga por la no exclusividad de los metros clásicos, interpretando el fenómeno versolibrista como una consecuencia natural de la renovación del lenguaje poético, lo cual no significa una ruptura total con el verso clásico. Para el autor es importante el diálogo entre ambos sistemas, puesto que, si bien el público está acostumbrado al verso regular, resulta provechoso expandir los horizontes expresivos, otorgándole variedad a los registros que puedan emplear los autores.

Lugones señala también lo siguiente: "La justificación de todo ensayo de verso libre está en el buen manejo de excelentes versos clásicos cuyo dominio comporte el derecho a efectuar innovaciones" (Lugones, 1909, p. 11). En ese sentido, el autor advierte que el ejercicio de la libertad debe sustentarse sobre un dominio de la tradición, puesto que la finalidad del verso libre es siempre la creación de nuevas significaciones, objetivo que exige conocer aquello que se desea trastocar o modificar.

El autor argentino encuentra en la rima un elemento que conecta al verso clásico con la configuración del verso libre como sistema prosódico. Esto se debe principalmente a que la rima, sea consonante o asonante, otorga mayor libertad a los creadores que las medidas silábicas rígidas, pero sin renunciar a 
nociones fundamentales para el verso como la musicalidad. Vicente Huidobro, en el prefacio a Adán (1916), comparte lo mencionado por Lugones en lo referente a la rima.

Huidobro señala que el poeta versolibrista puede romper con el isosilabismo si el tema abordado de lo exige, puesto que el verso libre constituye un nuevo tipo de metro, igualmente válido que el verso regular. De esta manera, el autor no cuestiona la condición de verso del verso libre, debido a que no se termina de romper con todos los elementos que contribuyen a crear el determinado impulso métrico.

En ese sentido, se puede afirmar que la rima es un elemento fónico fundamental que prevalece en el contexto de la vanguardia por su condición musical, siendo actualizada por un sistema prosódico como el verso libre. Asimismo, las reflexiones de autores como Lugones y Huidobro en torno a la nueva sensibilidad que propone el verso libre evidencian que dicho sistema prosódico constituye un fenómeno continental, capaz de adaptarse a los diferentes contextos de enunciación de la lírica latinoamericana.

En el caso de la presentación de la "Chinfonía burguesa", Joaquín Pasos expone los aspectos mencionados al principio del apartado, destacando el cuestionamiento a la figura del burgués, el interés por lo nacional y la renovación expresiva. El primero de estos, de la misma manera que en el contexto del movimiento Dadá, se debe a la pasividad de la clase burguesa para afrontar los problemas culturales de la época. El propio Coronel Urtecho, en un texto también publicado en 1931 ("Contra el Espíritu Burgués”), ya había señalado que la juventud debe oponerse a los valores de la burguesía para desarrollar el pensamiento crítico y fomentar la cultura en Nicaragua.

En este punto es preciso remarcar el contexto de enunciación de Joaquín Pasos al redactar la presentación de la "Chinfonía burguesa", puesto que, si bien la crítica a la figura del burgués se construye a partir de una ironía en el marco de lo 
absurdo, de claro cuño dadaísta, esta tiene como finalidad el establecimiento de una tradición propia. Así, los mecanismos del dadaísmo son instrumentalizados para elaborar un proyecto nacional, trascendiendo su contexto de negación total inicial.

El segundo punto central del manifiesto corresponde precisamente a la cuestión nacional, la cual implica una mirada sobre lo propio. Pasos, afín con lo propuesto por el grupo de vanguardia, no toma en cuenta el legado modernista de Rubén Darío, proponiendo un retorno a los "pequeños vestigios de la poesía popular tradicional" (Pasos, 2001, p. 164) para formular una propuesta de arte nacional.

Dicha operación refuerza la crítica hacia la figura del burgués, relacionado con el logos occidental, puesto que se opta por un discurso ubicado fuera de la racionalidad burguesa. Sin embargo, la consciencia sobre el arte precolombino no cumple una función exclusivamente crítica como en el quehacer dadaista, sino que adquiere profundidad al ser comprendida como el origen de la tradición que se trata de refundar.

Es así como Pasos, ante lo que él considera la ausencia de una tradición nacional, opta por combinar las prácticas vanguardistas como la redacción de manifiestos y experimentación con el lenguaje (incluyendo el uso de un sistema prosódico como el verso libre) con el contexto poético tradicional del país centroamericano para configurar un discurso que busca refundar la tradición poética en Nicaragua. El denominado género chinfónico es un ejemplo claro de lo mencionado, puesto que recoge "la alegría de atabales, trabalenguas y bombas sin faltarle la dulzura infantil de nuestras canciones de cuna y rimas infantiles" (Pasos, 2001, p. 164).

Los elementos mencionados en esta última cita determinan el tono de "Chinfonía burguesa" debido a que no solo operan en el plano conceptual del manifiesto, sino que son puestos en práctica a nivel formal. Dicha puesta en praxis tiene como eje principal a la rima, la cual permite la renovación expresiva 
pese a ser uno de los elementos fónicos más representativos de la tradición.

Esto se debe a que la rima permite crear el efecto de una musicalidad cercana a la poesía popular tradicional a través de las recurrencias fónicas, potenciando la ridiculización del burgués al enmarcarlo en un humor que infantiliza su accionar. Sin embargo, es pertinente remarcar que lo popular, al igual que el absurdo en el caso del Dadá, es un efecto conseguido a través de la organización minuciosa del lenguaje, de manera que el verso libre en el texto de Joaquín Pasos no constituye un retorno al verso irregular, sino una apropiación de lo popular a través de estrategias como el uso de paralelismos, onomatopeyas y juegos estróficos de carácter visual.

\section{E1 verso libre en "Chinfonia burguesa"}

Antes de proceder al análisis del verso libre en el poema, es necesario establecer una definición sobre dicho sistema prosódico. El verso libre emplea, al igual que el verso regular, ritmos fónicos y semánticos para crear efectos en el receptor. La diferencia radica, según Oldrich Belic (2000), en que el verso libre constituye un sistema prosódico "en el cual el número de elementos que producen el impulso métrico y obedecen a norma está reducido al mínimum” (Belic, 2000, p. 553).

Dicha reducción varía dependiendo de cada consciencia artística, por lo que el verso libre ofrece un amplio margen de acción de cara a la construcción de nuevas sensibilidades poéticas. Tal como señala Henríquez Ureña (2003), el verso en español puede ceñirse a tres normas básicas: la medida, el acento y la rima. No obstante, también existe la posibilidad de no seguir ninguna de las antes mencionadas. Así, el verso libre juega con esta posibilidad, estableciendo un diálogo orgánico entre sus propias particularidades y los diversos elementos del verso regular. Dicha condición dialogante es fundamental para la comprensión de este sistema prosódico. 
El análisis de Óscar Coello (2014) sobre el ritmo pedal en Trilce (1922) de César Vallejo es un ejemplo pertinente sobre lo planteado por Ureña. El investigador identifica que el poemario "está en verso libre, pero no solo está en verso libre. Hay poemas que no abdican de la métrica o la rima; y en ningún poema de los 77 del libro se abdica del ritmo" (Coello, 2014, p. 66). Asimismo, el quiebre de la sintaxis convencional, propio de las vanguardias históricas, se construye a partir de un manejo consciente del ritmo, por lo que el verso libre revitaliza la tradición métrica en lugar de romper totalmente con ella.

Continuando con Henríquez Ureña (2003), este plantea una noción genérica del verso, estableciendo el ritmo como unidad mínima para todos los sistemas prosódicos en diferentes lenguas. De esta manera, cualquier verso (sea libre o regular) puede comprenderse como una agrupación de sonidos que obedecen a leyes de repetición regidas por conceptos como el impulso métrico y la expectativa frustrada. Cabe mencionar que, en el caso del verso libre, estos conceptos operan de una forma diferenciada, renunciando al criterio silábico para trabajar con la repetición de unidades léxicas, sintácticas o temáticas.

Al respecto, Belic (2000) advierte que dichas repeticiones, basadas en la fonología oracional, centran su atención en el plano estilístico en lugar del plano métrico. Esto constituye un cambio de paradigma de cara a la concepción de la creación poética, puesto que comienza a construirse una nueva sensibilidad y, en consecuencia, una forma nueva de percibir el mundo mediante el arte.

La mención del término "mundo" no es casual, debido a que uno de los méritos del verso libre consiste en actualizar temas considerados universales, ampliando los horizontes expresivos del verso y siendo parte de los cambios de mentalidad que comenzaron a tener lugar de forma más constante durante el siglo XX. En ese sentido, no es una coincidencia que el trabajo poético de autores como los simbolistas franceses tenga lugar 
en la segunda mitad del siglo XIX, cuando ya se comenzaba a avizorar el afán rupturista que explotaria con las vanguardias.

Otro planteamiento pertinente es el de Pablo Jauralde (2004), quien señala que el verso libre ha tenido numerosos antecedentes a lo largo de la historia de la versificación. Sin embargo, el fenómeno versolibrista cobró mayor fuerza hacia finales del XIX con autores como Whitman, dado que este empleó dicho sistema prosódico de forma consciente, liberando al verso del esquema regular previamente definido para crear un nuevo efecto. Así, se evidencia que la libertad del verso debe responder a una mayor potencia comunicativa, puesto que se está subvirtiendo la tradición para ir más allá de lo ya institucionalizado.

Jauralde (2004) también advierte que el verso libre suele aparecer junto con el versículo y el verso irregular, diferenciándose de este último al trabajar sobre un fondo rítmico que responde a una idea de conjunto. Así, el verso irregular surge como una excepción en la tradición rítmica, mientras que el verso libre es una subversión consciente y gradual de esta. Dicha subversión de la tradición, como ya se mencionó, expande los horizontes expresivos, elaborando nuevas formas de aludir a temáticas que ya fueron abordadas por el verso regular. Asimismo, el versolibrismo permite la creación de nuevas temáticas en el marco de los proyectos modernos y posmodernos a lo largo de todo el siglo XX, generando - en suma- una nueva experiencia con el lenguaje poético.

A nivel latinoamericano, son icónicos los casos de Trilce (1922) y Altazor (1931), cuyos versos pueden leerse como la consecuencia de una nueva sensibilidad, así como un síntoma de la irrupción de nuevos modelos de mundo. Así, puede afirmarse que las múltiples posibilidades que ofrece el verso libre permiten un diálogo con la contemporaneidad, entendiéndola como un concepto relativo que refiere a un conjunto de valores determinados en cierto espacio y tiempo. 
En el caso de "Chinfonía burguesa", siguiendo la definición de Oldrich Belic, tres de los cuatro elementos fónicos fundamentales se ven reducidos a su condición mínima, focalizando la atención sobre la rima. En ese sentido, el verso libre en el texto se organiza a partir de un paralelismo de base fónica, el cual construye la sensación de impulso métrico y expectativa frustrada. Por ejemplo, en la sección "Andante Doméstico" la presencia de una onomatopeya quiebra la repetición de un esquema silábico que se apoya en el hexasílabo principalmente:

la mesa Teresa

la tortilla tiesa

la mayonesa

la salsa inglesa

la sssssssssssss... (Pasos \& Urtecho, 2001, p. 167)

Dicho quiebre evidencia que, si bien el ritmo es organizado a partir de la rima, elementos fónicos como la cantidad silábica cumplen una función auxiliar en la construcción del denominado impulso métrico. Asimismo, el fragmento presentado permite advertir la asimilación de una estética dadaísta puesto que el discurso se enmarca en los bordes de la irracionalidad, priorizando el juego con el lenguaje para generar un efecto de ironía.

Cabe precisar que dicha preocupación por la dimensión eufónica instrumentaliza los postulados dadaístas, adaptándolos a las exigencias del contexto nicaragüense. Así, la presencia de la onomatopeya citada no responde a un ordenamiento propiamente lógico en el plano semántico, sino a una distribución consciente del verso libre a través de un esquema oracional para generar el efecto de absurdo. En ese sentido, no es casual la repetición del artículo femenino en singular en todos los versos citados, así como el paralelismo fónico basado en la recurrencia del fonema fricativo alveolar (s). 
Adicionalmente, la rima se organiza a partir de la recurrencia de dos vocales abiertas, "e" y "a" respectivamente. De esta manera, la presencia de la onomatopeya no constituye una irrupción deliberada, sino una consecuencia de lo que el poema ha venido planteado. Estos mecanismos se repetirán en todo el conjunto, potenciando el planteamiento musical que ya podía advertirse en el título del poema y su división en siete secciones, de modo que se procederá al análisis puntual del poema "Preludio en forma de Burgués".

"Preludio en forma de Burgués" emplea un verso libre basado en el paralelismo de base fónica, que se manifiesta principalmente a través de la rima y la aliteración. Sin embargo, como se advirtió en el fragmento anterior, también cumplen un rol complementario otros elementos como la medida silábica, la distribución acentual y estrófica. Por ejemplo, la distribución estrófica, relacionándose con el título del texto, permite el establecimiento de una dimensión visual en el poema, lo cual contribuye en la potenciación del tono irónico en torno a la figura del burgués.

La representación irónica del burgués a nivel visual es determinante para otros aspectos como el tipo de lenguaje empleado y la extensión de los versos. Por eso la voz poética opta por la representación numérica (8) para representar visualmente el cuello el burgués, así como el uso de versos de mayor extensión para el torso de la figura. Además, esta distribución también posibilita una lectura que desiste de las pausas marcadas, de manera que el juego paralelístico discurre de forma continua.

Con respecto a la medida silábica, si bien el poema presenta una evidente polimetría de arte menor (a excepción de un eneasílabo hacia la mitad del texto), se puede advertir la presencia marcada del bisílabo. Dicho tipo de verso, sin que este llegue a convertirse en un patrón dominante, se intercala con el trisílabo, tetrasílabo y el verso de una sola silaba para construir un impulso métrico, el cual se ve constantemente frustrado: 
$\mathrm{O}$

$\mathrm{OsO}$

8

8

bolo bobo

Chón (Pasos, \& Urtecho, 2001, p. 166)

En ese sentido, es posible identificar un impulso métrico en la recurrencia de los bisílabos, la cual se ve frustrada por la presencia de un tetrasílabo (compuesto a su vez por dos bisílabos). Dicha expectativa frustrada determina un retorno al verso de una sílaba y el comienzo de un nuevo conjunto de aliteraciones. De esta manera, es posible identificar diferentes cambios de ritmo en el poema.

El fragmento citado también permite evidenciar la predilección de la voz poética por el uso de los troqueos, incluso en el penúltimo verso, el cual constituye el momento de expectativa frustrada. Cabe mencionar que una operación similar tiene lugar hacia el final del poema, donde la recurrencia de dos yambos se ve frustrada por un anapesto antes de retornar a un verso de una sílaba.

Finalmente, al estudiar la rima en el poema se advierte una predilección por las vocales "o" e "i". Sin embargo, a diferencia del primer fragmento citado, ambas no operan de forma conjunta. La vocal "o" construye paralelismos fónicos durante los dos primeros tercios del poema, mientras que el final emplea la misma estrategia con la vocal "i". Es así que la variación rítmica antes detectada se relaciona directamente con una variación vocálica.

Asimismo, la presencia de consonantes nasales como la " $\mathrm{m}$ " $y$ " $n$ " otorga un sentido de unidad al texto, puesto que la variación rítmica y vocálica se articula alrededor de un paralelismo fónico que incrementa su complejidad e intensidad a medida que se desarrolla el poema. En este punto es importante remarcar la intención de construir un arte nacional propuesta en 
el manifiesto, puesto que el uso marcado de dichas consonantes evidencia un interés por representar el habla popular desde una esfera poética consciente de la tradición occidental.

\section{Conclusiones preliminares}

El análisis de "Chinfonía burguesa", así como del texto de presentación a cargo de Joaquín Pasos ha permitido establecer que Pasos y Urtecho emplean un verso libre que se basa principalmente en el manejo consciente de los paralelismos de base fónica, el uso de la dimensión visual del poema, la onomatopeya y la rima tradicional. Asimismo, otros elementos fundamentales como la medida silábica y la distribución acentual cumplen un rol complementario, permitiendo el impulso métrico y la expectativa frustrada.

El verso libre de los autores actualiza la práctica dadaísta puesto que plantea un cuestionamiento al burgués basado en la ironía y un lenguaje que dialoga con el absurdo. Asimismo, dicha estética puede advertirse en el poema a través del uso de los paralelismos fónicos y la onomatopeya para configurar un discurso crítico, que parodia el accionar tanto artístico como social del burgués.

No obstante, el mérito de los autores radica en haber instrumentalizado la práctica dadaísta para configurar una nueva sensibilidad a principios de la década del 30 en Nicaragua, elaborando un proyecto nacional de corte vanguardista y rompiendo con la estética modernista que había comenzado a perder vigencia en la región. En ese sentido, el texto Joaquín Pasos y José Coronel Urtecho resulta fundamental para comprender el desarrollo del verso libre en Latinoamérica, puesto que este desarrollo permite el diálogo entre una estética de ruptura como el dadaísmo y un proyecto de fundación de una tradición poética en Centroamérica. 


\section{Referencias bibliografias}

Aguirre, R. (1968). El dadaismo. Buenos Aires: Centro Editor de América Latina.

Belic, O. (2000). Verso español y verso europeo. Introducción a la teoría del verso español en el contexto europeo. Santafé de Bogotá: Instituto Caro y Cuervo.

Bellini, G. (2010). Notas sobre la evolución de las vanguardias en Centroamérica: Nicaragua. Biblioteca Virtual Universal.

Breton, A. (2001). Manifiestos del surrealismo [2a . Ed.]. Buenos Aires: Editorial Argonauta.

Cardenal, E. (1982). El grupo de vanguardia en Nicaragua. Revista de Crítica Literaria Latinoamericana, 8 (15), 71- 76.

Chiriboga, A. (2014). Desencuentros en la vanguardia literaria: Nicaragua, Guatemala y Costa Rica. (Tesis para optar por título de Doctora en Filosofia), University of Pittsburgh, Estados Unidos.

Coello, O. (2014). La poética del gran disparate y el ritmo pedal de Trilce. Boletín de la Academia Peruana de la Lengua. 58 (58), $61-75$.

De 1' Ecotais, E. (1998). El espiritu dada. París: Assouline.

De Torre, G. (1965). Historia de las Literaturas de Vanguardia. Madrid: Visor Libros.

Fajardo, C. (2011). Vanguardias artísticas del Siglo XX. Colombia: Le Monde diplomatique.

Henríquez Ureña, P. (2003). Obras completas. Tomo III. Estudios métricos. República Dominicana, Santo Domingo: Secretaria de Estado de Cultura.

Huidobro, V. (1916). Adán. Santiago: Imprenta Universitaria.

Jauralde, P. (2004). Verso libre y verso irregular. VOZ Y LETRA, 15, $115-128$.

Lugones, L. (1909). Lunario Sentimental. Buenos Aires: Casa Editorial Sopena.

Solís, P. (2001). El movimiento de vanguardia en Nicaragua. Análisis y Antología. Colombia: Fundación Vida.

Tzara, T. (1924). 7 manifiestos dadá. París: La cucaracha ilustrada. 